\title{
Addressing digital inequalities amongst young people: Conflicting discourses and complex outcomes
}

\author{
Sarah Wilkin, Huw Davies, Rebecca Eynon
}

For publication in the Oxford Review of Education

\begin{abstract}
Despite the ongoing discourse about the constantly connected and digitally savvy youth in the UK, a growing evidence base demonstrates that there are still significant inequalities in young people's ability to access and use the Internet. There is a small, but significant, proportion of young people who do not have Internet access at home, nor have sufficient digital skills to engage online in ways that are meaningful to them.
\end{abstract}

This paper presents findings from a two-year school and local council run initiative in England to provide 30 such digitally disadvantaged young people with a laptop and stable Internet connection at home as well as school support. Drawing on rich qualitative data (home and school visits; parent, student and teacher interviews), we explore the experiences of young people, parents and teachers who were part of this digital inclusion scheme. Specifically, we examine how the long-standing essentialist discourses around 'digital youth' and determinist ideas of technology and social change inform how such a scheme is perceived, enacted and experienced by the teachers, parents and young people involved with the initiative, as well as the implications these discourses have for the ways the outcomes of such projects are judged.

\section{Background}

In many countries, a rhetoric centred on a so-called 'digital youth' prevails whereby today's teenagers are said to have been naturalised into a world of technology which they navigate and negotiate with confidence; always seeking opportunities to be connected (Prensky, 2001; Oblinger \& Oblinger, 2005). Within this over-exaggerated paradigm, age is the overriding factor determining their engagement with technology. In many cases, this rhetoric is drawn upon to pigeon-hole and appeal to various sectors of the general public usually as part of a commercial campaign to market a service or product (Holmes, 2011; Selwyn, 2003).

Alongside this positive essentialist discourse has been one of concern: concern about young people's overreliance on (and in some cases an 'addiction' to) the Internet and digital technology (Buckingham, 1998; boyd, 2014). These concerns are discussed alongside issues of safety where young people need to be protected from inappropriate content and dangerous individuals (Selwyn, 2003). In this way, young people are positioned as both hapless victims unprotected from the pressures of an increasingly digital world, and agents of change who can harness the wealth of online resources available to master their own destiny (Buckingham, 1998; Holloway \& Valentine, 2003).

Empirical research has demonstrated that the ways that young people engage with technology varies considerably: few comply with the 'digital youth' orthodoxy (Helsper and Eynon, 2010). Young people have to navigate between both the opportunities and the risks that new technologies can afford (Livingstone, 2009) and this produces variations in practice. Despite the extensive amount of research, and the replication of these findings in multiple countries using varied research approaches, essentialist and conflicting discourses about young people endure; even if the terminology changes. This is in part because of society's complex relationship youth, wanting both to protect them but also viewing them as leaders in our optimistic technological future (Facer and 
Furlong, 2001). These simplistic discourses are unhelpful for all young people, their parents and guardians, and for those who educate them. However, perhaps the most impact is felt by those young people who do not have ready access and skills to use technology (Eynon \& Geniets, 2015).

Research on digital inequalities has moved away from a binary focus on access or no access to technology, and now encompasses a more nuanced understanding of Internet access being situated in a complex web of social, economic and cultural factors (Selwyn, 2004; Allen, 2010; Van Deursen \& van Dijk, 2014). As part of this debate, there is a significant emphasis on how digital ability and knowledge along with access, can shape an individual's use of technology (DiMaggio \& Hargittai, 2001; Hargittai, 2002). To own digital equipment is just the beginning; to know how to use it 'meaningfully' and achieve ambitions requires a great deal more application (Van Dijk, 1999).

Despite many assuming that digital inequality is inapplicable to younger age groups, a large number of studies have documented the varied ways that young people use the Internet and shown clear relationships in how quality of access, motivations and skills are all positively related to certain ways of engaging online (Micheli, 2015). For example, survey research with young people in Britain demonstrates how young people who are disadvantaged via access and/ or skills tend to use the Internet for a narrow range of purposes (Livingstone and Helsper, 2007). Robinson's (2009) qualitative study in the US demonstrated that young people who had to use the library to access the Internet, prioritised seeking information for homework over using the Internet for leisure purposes (playing games, browsing to find out more about their hobbies etc.). Leisure represented a luxury they could neither afford nor justify in their situation when they had to queue for a timed slot on a public computer. Therefore, it seems that young people who are disadvantaged via access and/ or skills can be seemingly locked into patterns of narrow, task-orientated Internet usage.

There is then, a significant disconnect between the discourses around young people's uses of technology and the everyday realities for at least some young people. These discourses are largely immune to evidence because they reflect the interests of a variety of stakeholders (Friesen, 2008). In turn, they help shape educational policy and practice, often with limited understandings of what it will achieve (Friesen, 2008; Livingstone, 2012). Indeed, these determinist views about the relationship between technology, society and youth are salient in educational policy and practice across the globe. Pertinent to this special issue is the worldwide plethora of one-to-one computing initiatives which sometimes rather straightforwardly links the provision of individual access to technology with improvements in educational outcomes, and in some cases inequalities in society more generally (Warschauer et al., 2011).

This paper focuses on the experiences of 30 young people living in England, who were provided with a free Internet connection (either broadband or a dongle) and laptop, alongside skills training as part of a two-year school and council run initiative. In doing so, we aim to examine how the conflicting essentialist discourses surrounding young people and technology influence how digital inclusion schemes are enacted and experienced; and effect the scheme's outcomes. Prior to this, the young people in this study either had no means of connecting to the Internet or had intermittent access through alternative devices such as a smart phone. Such a scheme has obvious overlaps with many other one-to-one initiatives, but is different in important ways in its attention on the home environment and the provision of laptops and the Internet only to those who do not have them.

There is a significant history of providing young people with access to technical devices to address issues of both digital and educational inequality. However, a number of digital inclusion schemes, for both adults and young people all have demonstrated that the reality is far more complex than often envisaged by the optimists (Selwyn, 2014; Straubhaar et al., 2012). Frequently, the outcomes of such 
schemes fail to meet expectations; and beyond practical factors that could potentially be improved (better quality devices or targeted skills training) previous research has pointed to the need to better examine the political, economic and social factors that surround such initiatives; and the underpinning (although often implicit) perspective on social inequalities in society (Clark, 2003; Tufekci, 2012).

Quantitative studies that have tried to isolate the impact of technology access and skills on educational outcomes have arrived at mixed results and suffer from a range of methodological challenges (Biagi and Loi, 2013; Livingstone, 2012; Pagani et al., 2016). However, more qualitative work that examines how young people experience technology situated within the wider context of everyday life highlight how 'levelling the digital playing field' is important (Davies and Eynon, 2013). Digital access and skills alone cannot transform the life chances of young people (Selwyn, 2014). Yet without a way for young people to engage with technology in ways of their choosing puts young people at social and educational disadvantage. This is particularly the case in a society where technology is often used as mechanism to provide support, learning and employment opportunities, and represents an important part of youth culture. Thus, home access can then be viewed as a "necessary (though not sufficient) condition" for participation in everyday life mediated by technology (Lievrouw and Farb 2003, p.503) to the extent to which young people wish to use technology for this purpose. It is within this more pragmatic view that the current initiative is examined.

\section{Methodology}

The scheme was intended as a collaborative endeavour between the local city council who procured the Internet connections, the schools who purchased the laptops and committed to providing skills support to the students, and the academic team who were initially engaged to research the programme and provide academically informed advice at all stages of the project.

30 students from three 11-18 mixed secondary comprehensive schools in England were involved in the initiative, all of whom were about to begin their 2 year studies for the GCSEs ${ }^{1}$. Each school had a different catchment area, cohort and set of ongoing issues:

- School Red: a large, oversubscribed, high achieving school which attracts a wide range of students - many from the affluent families living in the surrounding areas but also a considerable number from disadvantaged homes. Raising levels of attendance is an ongoing area of focus.

- School Yellow: assessed as 'good' according to OFSTED'2. It attracts a diverse cohort of students many with English as an additional language and receiving Pupil Premium ${ }^{3}$. There is also a higher than average number of students with disabilities and special educational needs.

\footnotetext{
${ }^{1}$ The General Certificate of Secondary Education (GCSEs) are public examinations taken by 16 year olds in England and Wales. They typically include Mathematics, English, Sciences and a number of other subjects as selected by the student.

${ }^{2}$ OFSTED is the Office for Standards in Education, Children's Services and Skills. They inspect and regulate services that care for children and young people, and services providing education and skills for learners of all ages.

${ }^{3}$ The pupil premium is additional funding for publicly funded schools in England designed to help raise the attainment of disadvantaged pupils and close the gap between them and their peers.
} 
- School Blue: a larger than the average comprehensive school. It serves an area of significant social disadvantage. Just under half of students are from among the most deprived wards in the country. There is relatively high movement of students in and out of the academy in comparison with that found nationally. More than half of students on roll receive Pupil Premium and there are a significant number of students who have disabilities and/or special educational needs.

The research team worked with the schools to systematically assess which students would most benefit from the scheme, accommodating the differing preferences of each school: School Red used a survey by the researchers to identify a list of students for researchers to interview and then evaluate 'need' based on these discussions, and Schools Yellow and Blue decided internally which families they wanted researchers to focus on depending on school priorities. The cut off between eligible and not eligible was blurred and difficult to define - particularly as people can move in and out of use of technology at home (Wilhelm, 2000). This study represents a snapshot of who was considered at most 'need' within the three GCSE cohorts when the project began in 2014.

The young people who were part of this scheme were typically from low income households and / or where parents / guardians did not use the Internet. They were a diverse group, evenly split in gender balance, with a broad range of prior educational attainment, with some students with English as their second language. They often qualified for pupil premium or free school meals. Family arrangements were multiple, some were from two parent households, others from single parent households, some young people lived with extended family or carers, and one student was from a traveller community. A great deal of research in this domain has evidenced the positive relationship between digital and social inequality (Eynon \& Malmberg, 2012; Hargittai \& Hinnant, 2008; Peter \& Valkenburg, 2006) and the case was similar in this current project.

To best capture the rich context surrounding the scheme and the families, a range of data collection methods was utilised. Initially the research was conceptualised as a mixed method evaluative case study design; with pre and post-tests of digital skills and an array of social and learning measures, alongside qualitative interviews. However, as the initiative progressed and the research team's role shifted from one of evaluator and advisor to the main implementer of the programme (due to staff changes among other challenges), the research became a primarily qualitative study that utilised ethnographically informed interviews and observations. This was in order to "systematically pay attention to the often contradictory ideas, thoughts, perceptions, interactions and meanings of the people" that were at the heart of this initiative (Swanborn 2010:151); focusing on the everyday pursuits of individuals as they participated in the digital inclusion scheme (Stake, 1995).

The analysis here focuses on the data collected from recorded sessions with students (where they received one to one skills support in schools from the research team) and semi-structured interviews with lead teachers, parents and council/community staff. The research team were constantly engaged with the initiative over the two years, and many other data sources have indirectly informed the analysis; including notes from meetings with teachers, school leaders, the Internet Service provider and the council, emails between all the stakeholders working on the project, materials produced for the council and schools etc. This enabled the research team to understand the student experience of the scheme from a range of perspectives (Richardson and St Pierre, 2005).

The interviews were carried out face to face in a range of settings - at school, at home and in community centres. This involved: 83 individual consultations in schools with the students to offer skills training, 19 interviews with students and parents at home, interviews with the lead teacher(s) 
from each of the three schools, and insights from 2 community workers and 1 volunteer who worked for the project's Internet Service Provider. All interviews were recorded and transcribed for analysis.

There were a number of significant practical challenges with this project: poor quality equipment, significant delays in fixing connectivity problems by the ISP, issues with teachers having limited time to provide skills support and excessive filters on the laptops. These are discussed in detail elsewhere (Davies et al., 2017); and indeed are commonly cited as issues in one to one lap-top programmes in various contexts (Warschauer et al., 2011; Warschauer and Matuchniak, 2014). As suggested in the introduction, the analytical strategy developed was designed to draw attention to a wider set of social forces at play that influence such schemes as opposed to these more practical factors.

In line with Richie and Spencer's 1994 'framework model', the research team utilised varied strategies to look for and develop themes and connections between what each participant and groups (parents, young people, teachers) reported in order to provide explanations for the participants' use of technology, and compare and contrast against popular discourses associated with (disadvantaged) young people and the Internet. Particularly given the closeness of the research team to the project and the strong desire to make the project 'a success' a reflexive approach was taken throughout, in the form of reflective note taking at all data collection phases and weekly team meetings to discuss and reflect on the events of the previous week (Clark, 2012; Pillow, 2003).

Beyond the standard University ethical protocols and approvals that were followed, this research presented a number of important ethical questions. First was the risk of participants feeling obliged to take part in interviews since they had been given a device and Internet connection for free. As Denzin (2001:24) notes, 'doing interviews is a privilege granted to us, not a right that we have'. It was made clear to participants throughout the study that any home visits and time spent talking to the team was entirely voluntary and they could opt out at any time, and support sessions would still be provided. Indeed, additional incentives (e.g. a shopping voucher) were offered to families as a 'thank you' for taking part in home visits, to highlight the optional nature of such an activity.

Relatedly, the research team were mindful of the unequal power dynamic within the interviews (Kvale, 2006) and took a sensitive approach inspired by Sinding and Aronson (2003) to ensure that all participants felt continually valued. The researchers had a complex role in the project and were viewed in different ways by participants (researcher, mediator, technician, teacher). To further complicate matters, many of the families were quite accustomed to outsiders (e.g. social workers) coming in and asking them to supply information, and many families volunteered very private details to the team about their lives indicating that the researchers were often seen as people in some form of official capacity. As Miller and Glassner suggest interviews can be a way of empowering marginalised groups in society and potentially fostering social change (Miller \& Glassner, 2010); yet awareness of, and respect for, these unequal power dynamics remained an important consideration in the analysis and writing up process.

\subsection{Findings}

\subsection{Project outcomes}

The essentialist discourses discussed in the introduction would imply a number of outcomes for this project: a transformation in the way that young people used technology to encompass a far broader and more creative set of technology practices, clear improvements in ability to use technology and a positive impact on a wide set of education outcomes. However, the reality was significantly different. Most young people remained relatively narrow, consumers of the Internet. They tended 
to use their laptops and the Internet for searching for information for research-based homework tasks, communicating via social networks, and accessing different media types for entertainment value (games and videos); and relied on a handful of well-known and/or recommended websites to fulfil these aims, typically, MyMaths and BBC Bitesize for homework, YouTube for streaming videos, and Facebook for contacting friends. For some young people there were clear social and learning benefits, but their uses of the laptop and Internet at home did not have for the most part a 'transformational' impact on their education and everyday lives in line with the more optimistic expectations of 1 to 1 initiatives (see also Clarke, 2003). Instead, there were three kinds of positive outcomes that the young people involved in the initiative experienced to varying degrees.

\subsubsection{A means to take ownership of their studies and everyday life}

For many of the participants, the Internet was a useful tool to them. It did what they wanted it to do. It kept them up to date with what was going on in their social circles, enabled them to complete homework tasks, and provided entertainment and a means to look up simple information. For some students, the new changes in their home learning environment meant that they felt more motivated to complete their homework and make progress in their subjects. Katie told us how she is able to catch up with missed work and revise for her exams in her own time and in the comfort of her own home; before she had to go over to a relative's house or the library. Thus, she can go beyond the work set by her teachers and take more control of her studies:

'[I have] become more confident in school' as it helps her to achieve the grades that she needs: ' $[$ I am] always willing to get involved [in class] and before I wasn' $t$ '.

Likewise, for Georgia, who speaks English as her second language, acquiring access to online translation tools has enabled her to gain a better understanding of the work teachers set her and gain more confidence in her studies. This is because she could look up unfamiliar words and read about them in context in her own time.

One of the most inspiring cases in the project was Paul's. Previously, he had been suffering from problems with depression, refused to attend school and isolated himself away from his friends. However, since having access to the Internet and a personal device, he felt more motivated to conduct his own research for schoolwork, find out about future careers and maintain friendships that had started to become distant. Paul's mother explained that:

'it's given him more incentive to find things out for himself, make note of them on the laptop, and then refer to it back to school with his work(...)And it's reconnected him there as well [to his friends](...) he knows what he wants to do when he leaves school (...) It's completely boosted his self-confidence. He's always been technically minded anyway, but this has just brought it on even further'.

Though Paul's story was particularly unique within the study and other factors may have contributed, the project had enabled Paul to use the Internet in ways that were meaningful to him in his life. It represented a place where he could escape to, immerse himself in information on topics that intrigued him, and it enabled him to take back some control over specific aspects of his life (e.g. school work, career planning). Like all the young people in this study, none of his uses of the Internet are particularly creative or extraordinary - but nonetheless the initiative gave many of the young people a greater sense of ownership over some aspect of their lives.

\subsubsection{The luxury of choice}


Most notably, this research suggested the importance of having a device that is available and suitable in its design to achieve a range of outcomes. In many ways, this appeared almost as essential to the participants as the Internet connection itself. Anna commented on how 'it made things easier... you do not have to hold the device (like you would with a phone) to watch videos'. In families with multiple children, there was often competition to use devices and some siblings were prioritised over others due to the particular stage of their education. For example, concerns were raised after one of the participating families encouraged their oldest child to take the project laptop with them to use at university, thus denying the originally selected student to gain Internet access on their own personal device.

Moreover, some of the students owned tablet computers but despite this seeming advantage they still confirmed the value of having a laptop since it was convenient to organise and write up their work. Ellie explained how she would move between her iPad for researching particular topics and images, and her laptop for collating her work and typing it up.

Some of the students viewed acquiring the laptops as an opportunity to more effectively divide certain areas of their lives (leisure vs work and private vs public) rather than merge all that they had previously done on a phone (if they had one) on one device. This is because many reported that they often used their laptop to perform certain work-related tasks (I.e. conducting research, planning their essays) and their mobile phone for more informal, leisurely pursuits (i.e. communicating with friends and family, playing games).

\subsubsection{A way to support social integration}

The social aspects of the Internet were also valuable to many young people in the study, in ways that reinforced existing networks as opposed to developing new forms of social capital. Several of the students explained how since gaining Internet access they had been able to positively build upon their existing relationships with friends and family: social networking tools were central to this process. For example, Billy stated how he enjoyed the ability and ease with which to make more frequent social arrangements with his father through Facebook; he could circumnavigate awkward and strained communications between his parents.

A number of the students offered examples of how their experience with online media had positively shaped their leisure activities offline and connected them with their friends. Brandon, who plays for his local basketball team, told us about how he enjoyed trying to improve his technique by watching relevant YouTube videos. On one occasion, after watching a video on blocking, he adapted his performance in a match and helped his team win the game. Similarly, Eden and her family subscribed to NetFlix (an online library of films and television programmes). As a consequence, she could better contribute to conversations among her friends about popular media and trends.

\subsection{The persistence of narrow use - did the project 'fail'?}

Most of the young people in this research would be termed as 'basic' or 'moderate' users (Livingstone \& Helsper, 2007) or 'passive consumers' (Jenkins et al., 2006). This is because they employed the Internet to serve a relatively narrow range of purposes and, based on interviews at the outset and end of the study and discussions within the students in the one to one sessions, this remained the case for the majority of the participants throughout the project.

Usage was predominantly purpose-driven rather than experimental or overtly creative. A more reserved attitude stood in its place even when given the opportunity to discuss and be supported in expanding their Internet usage during one-to one skills' sessions. This is not to say that their web 
usage did not include some level of risk as certain gaps in their digital knowledge (i.e. in relation to web evaluation and staying safe in social networks) meant they inadvertently put themselves in vulnerable situations. One student, for example, reported being subject to cyber bullying on Facebook whilst another received negative comments after posting a music video online. However, it was not evident in many of the interviews that many chose to spend much time trying out new digitally mediated activities.

Thus, for the most part, the participants in this study began and remained relatively narrow users of the Internet for the two years of the initiative. Despite the improvement in access and support, these young people did not align with the digital youth rhetoric, nor broaden their uses of the Internet in the ways that other researchers have proposed (Livingstone and Helsper, 2007). Relatedly, while the one to one sessions did support the students to some degree, we are not convinced that they led to a significant increase in a range of digital skills as originally envisaged at the outset of the project (a view also supported by the teachers).

Such outcomes may seem like a failure of the initiative. Yet, it is likely that this relatively narrow use is in large part a consequence of various socialisation processes, subcultural interests and individual motivations which mean that more niche or creative forms of Internet use possess limited relevance to their lives - irrespective of their accessibility (Buckingham, 1998). Furthermore, as Gunkel (2003:507; see Holmes, 2011) argues, interpretations which position young people - who make lowlevel, narrow or no use of the Internet- at the lower end of a continuum and in 'various stages of deficiency ... [can be] arrogant and paternalistic'.

Indeed, for a significant proportion of the young people engaged in the project their uses of the laptops and the Internet connection were useful to them; and in that sense was a 'success'.

However, there is a balance to be struck here; it is not appropriate to straightforwardly celebrate all young people's uses of the Internet and simply ignore the complex relationships between digital and social inequality more broadly.

\subsection{A focus on practice}

Viewing the 'uses' reported above as a set of practices (Sims, 2014), draws attention to the wider social, political and economic context in which such schemes take place. In doing so it is possible to see how the essentialist discourses around young people and technology shaped the way the programme was enacted and in fact may have stymied some young people's uses of technology; perhaps reinforcing the inequalities that the programme was designed to address.

\subsubsection{The positioning of young people}

The young people's past experiences of going online alongside popular discourse about young people and technology shaped their motivation and interest in using the Internet. In contrast to much of the digital youth discourse, for some students; the motivation to go online and explore it for enjoyment was simply not present. For example, Nina explained that:

'On Instagram you need to upload pictures and stuff, that's not me and Facebook is quite boring, like always seeing what people upload, it's just not me, and Twitter I just don't know how to use it and I just don't like it'.

This lack of interest in connecting with others in this way could represent a personal preference and sense of identity (Davies and Eynon, 2013): 'it's just not me', setting herself against the digital youth 
discourse. Nina's approach meant she could claim greater ownership over her online behaviours especially in relation to social networks that are so frequently (and wrongly) assumed to be used frequently by all in her generation. Facer and Furlong (2001) describe this phenomenon as a way for young people to construct their definitions of what it means for them to be 'successfully young' by distancing themselves from technology for reasons of access, skills or interest.

Indeed, Nina's somewhat frustrating experiences of using the Internet previously may have tainted her on going relationship with technology (Goode, 2010; Eynon \& Geniets, 2015; Schofield-Clark, Demont-Heinrich \& Webber, 2005). A lack of skills could also have been a factor for Nina, as her statement above could represent a defence mechanism in that she turns her lack of digital skills into a strength by framing it as a choice (Schofield-Clarke et al., 2005). While Nina's case is a particularly strong example, throughout the interviews it is clear that the optimistic discourses about digital youth shaped the ways that some young people perceived and presented themselves in relation to technology.

\subsubsection{Familial factors}

From the outset of the project young people's experiences and uses of the Internet were influenced by those around them (Buckingham, Banaji, Burn, Carr, Cranmer \& Willett, 2006). The home and other family members formed an important part of this complex set of influences, often clearly shaped by popular discourses discussed in the introduction. Family expectations could enable but more often stymied their child's online activity, often due to concerns about safety. For example, Joe's mother (Molly) was worried about the risks of him venturing alone on social media websites:

'You're not old enough for Facebook at the moment are you, well you are but you're not that computer savvy at the minute. That's probably what will be the next thing I think. Especially when you leave school and that's one of the quicker ways to keep in touch isn't it?'

Despite her own enjoyment of using Facebook and perhaps due to Joe's learning difficulty, it seemed that Molly wanted to protect him from the public arena of social networking until she was convinced that he had a genuine need for it. Cara's relatives also explained that they kept a close eye on her Internet history beyond her use of the web for homework. Although parental interventions like these were well-meaning, they represented constraints for the students. Indeed, these safety concerns, often seen in the popular discourses about young people, have been also highlighted in other studies of home use of technology (e.g. Holloway and Valentine, 2003; Tripp, 2011).

Parents and guardians, even when they were not particularly frequent or expert users of the Internet themselves, often believed in the value of technology for homework and for future economic success. At times, these beliefs led to a desire for their child to use the laptop for the 'correct' purposes and prioritise formal learning activities over entertainment or socialising. For example, Hannah told us that she wished the school would give her daughter more specific work based tasks on the laptop to improve her skills.

'Give them little tasks or something, you know, just to keep them thinking about school because, you know, it is easy just, for me to just wander off and then she's on League of Legends for two hours, where, you know, I think if something came through that she had to sort of stick to and she had to produce it, it might, I don't know, help her manager her time better'.

Similarly, Caroline was unsure about the blend of school and leisure activities that a laptop and Internet connection afforded: 
'I'll go in and I'll say, "I thought you were doing homework". [My daughter says] "Well I am but [my friends] helping me because we were stuck on this question." I think, "Okay, fair enough, as long as you're actually doing it."'

This prioritising of formal learning opportunities and viewing the laptop as primarily a way to support education and employment chances is unsurprising, particularly given the numerous advertising campaigns that stress the importance of technology for a child's educational future (Buckingham, 2007); and also chimed closely with family values and priorities (Alper et al., 2016).

Where parents lived apart, this sometimes presented further challenges to the young people since they were not only having to negotiate between multiple spaces (some they could gain access in, some they could not) and differing parental expectations but also varying levels of support (one parent might be more digitally adept than the other). That said, it could be argued that the students in this study were, to some extent, better equipped to handle this changeable situation than others who had always known a stable connection, since 'opportunist surfing' had been a feature of their usage of technology for many years.

\subsubsection{Conflicting school cultures}

An important part of this study was to provide both Internet access and support for young people to develop their digital skills, as this has often been shown to be an important factor along with access in shaping the way young people engage with the Internet (Eynon and Malmberg, 2011; Hargittai, 2010; Hargittai \& Shaw, 2015; Livingstone \& Helsper, 2010). As noted above, the place for this support was deliberately chosen to be the school. However, this choice was not without its challenges.

The teachers in this study were divided in their opinion on what value the initiative could add to the students' lives. Many of the staff viewed the scheme as an opportunity to encourage the students to feel more included in the activities of their peers. School Red hoped it would help close gaps in terms of the students' academic performance but also their sense of self and well-being. Likewise one of the lead teachers at School Yellow stated that because of the barriers pupil premium students face this initiative was important for, 'levelling that playing field in some regard'. The same member of staff also recognised the holistic benefits the Internet can bring if harnessed effectively, which embraced some of the uses that the students valued:

'An effective Internet user is someone who can use it both for entertainment, creativity, work and personal usage and anyone who can reference when and where and how to use the Internet in those different contexts'.

Yet, this apparent openness was accompanied by a degree of restriction - often imposed on them by senior management. For example, at the same time as wanting students to 'feel part of the same picture', School Red placed rigid filters on the laptops, and staff often gave students specific web addresses to use for homework tasks rather than asking them to seek information for themselves:

'we can't give them the freedom...opening it up takes them in all wrong directions to what we want them to achieve'.

At School Blue, staff strongly believed that the project solely represented a means to help the students academically. It was especially essential as all homework in the school was set, monitored and submitted online. However, they were highly sceptical of the merits of using the Internet for social networking and other leisure activities since: 
'the majority of times, if we do have an issue here...it is caused outside of school from someone saying this, this and this and it is over social media, and that gets brought into school and then it has to get resolved'.

Consequently, they too had heavy filters on the school computers and there was a zero tolerance policy on the use of smart phones on site. To staff, the Internet had the potential to be as much a burden as it was an asset, if not managed carefully.

In a similar vein, one of the local community workers spoke about the problems the council faced when they tried to run free IT courses for children in the most socially deprived areas:

'it caused massive headaches. Because the kids would treat it as a youth club activity, and you'd have kids going in there that didn't really want to do IT. They wanted to muck around and go on YouTube and do all the things that, you know, get onto sites that they shouldn't be on'

Indeed, 'informal' and social uses of the Internet valued by young people are not accounted for in the National Curriculum in England other than in reference to online safety (Department of Education, 2013). This along with a dismissal of the value of such practices among educators can be counterproductive since it is clear that such activities hold great significance to the young people they work with (Livingstone, 2003; Greenhow and Robelia, 2009; Jenkins et al., 2006). Informational uses of the Internet are not the only ways young people can learn from digitally mediated practice (Boonaert and Vettenburg, 2011).

Each of the examples above reveal the tensions which can unfold when educators have to navigate a conflicting set of discourses about young people and technology. It is difficult for those working with young people to negotiate a balance between encouraging them to use a wide range of resources but also taking care of their online/offline safety and pushing them towards the educational outcomes they are predicted to achieve.

\subsection{Discussion and conclusion}

Young people's relationship with technology is complicated. Their beliefs, uses and experiences of technology are shaped by their past experiences and the digital youth discourse. It led to some of the young people participating in the current project to feel as if they had to defend their choices of their uses of the Internet for a relatively narrow and perhaps not that 'exciting' range of activities; and in some cases to mask the skills that they were lacking. Awareness that their uses of technology are not 'the best' ones or those that are most valued by society can serve to exacerbate feelings of exclusion (Davies and Eynon, 2013; Sims, 2014).

Although the young people's engagement with the Internet in this project was neither sophisticated nor varied, it did what they needed it to do within the wider context of their lives. They could now take ownership of their studies, better maintain friendships and access a wider range of entertainment media (games, music and films) to be more social connected and have a certain freedom over what device and where to connect online. Arguably, these kinds of usage are in fact fairly typical of all teenagers, as few young people (regardless of social class, access, or skills) meet the 'digital native' rhetoric (Eynon and Malmberg, 2012). This suggests the need to apply a socio cultural lens to exploring young people's digital practices that account for the wider social context (Boonaert and Vettenburg, 2011; Sims, 2014).

Digital youth discourses do not benefit anyone. Similar to other studies we have seen how parental engagement with their child's uses of technology in the home can be significantly influenced by these popular understandings (Valentine and Holloway, 2003). This includes beliefs held by the 
majority of the parents that technology is important for their child's education and future, yet they must also be protected from it. This is perhaps made harder for this group of parents as often they did not have many skills or much experience of technology themselves; and often looked to the school for additional support. Ensuring that their children used the Internet safely and in the 'correct' way was of upmost importance, even if well-intentioned concerns about safety negatively influenced the experiences of the Internet for the young people themselves.

At the same time, schools in England are under pressure to support uses of technology that link to the digital youth discourse, focusing on niche activities like coding or creating content while at the same time locking down systems to address safety concerns, and prescribing specific websites to explore so young people do not waste their time 'going off topic'. Such discourse also influences teachers in the way they understand and experience technology and their relationships with their students (Bayne and Ross, 2011:160). Indeed, teachers are often made to feel powerless in such debates, as young people are positioned as the "expert" (Helsper and Eynon, 2010). Schools and teachers are then left in a strange and unhelpful position when engaging in a digital inclusion schemes, having both to overcome a perceived lack of expertise to teach perceived economically valuable skills such as coding, while at the same time ensuring young people's experiences of technology are controlled and protected.

Despite the challenges for schools, they remain a hugely important site for such initiatives; particularly where family members have little if any digital experience. The resilient discourses around digital youth that inform educational policy are unlikely to end anytime soon; suggesting that if formal education is an important site for supporting digital inclusion, then change has to come from within schools themselves. Indeed, Sachs highlights how through collaborative practice teachers can develop an activist identity that leads to new ways of thinking and enacting the role of the teacher in contemporary society that stands in opposition to more popular managerial and entrepreneurial discourses (Sachs, 2001). While not specifically about technology per se, it is possible to see the parallels. This is supported by Biesta's insightful and persuasive argument that schools should take a responsible as opposed to responsive position to education for the global network society that takes a more critical stance about the kind of society we are educating for (Biesta, 2013).

Inclusion programmes like the one discussed in the paper provide some of the necessary but not sufficient conditions to address digital inequalities. It is important to look to the wider social conditions of which these programmes are part and how these social, economic and political contexts can reinforce or stymie the success of such initiatives. There is a need to move towards a more holistic understanding of social and digital inequality and try to deliberately develop schemes that use technology to question and change the status quo. Ensuring regular and flexible technical access is an important ingredient, but changing teaching to facilitate the development of digital literacies, changing the assessment culture to measure what is valuable to society, alongside out of school youth programmes to support technology use and further academic research are also all necessary to begin to help educators shape this area of social and digital life (Warschauer and Maruchniak, 2010). As Friesen (2008) suggests, studies such as the one reported here that highlight the inherent tensions between popular discourses and everyday experience may make it possible to find new way of engaging with, and critiquing, in-built assumptions and values about youth and technology and try to reshape the agenda for schools and young people in the future. This can be achieved through a more collaborative and participatory approach to the design of these initiatives, and an agreed sense of what 'success' of such schemes can look like that is based on local 
experiences and understandings that explicitly critique and acknowledge the popular discourse of digital youth.

Acknowledgements: The authors of this paper would like to thank Dr Tracey Calabrese, Dr Laura Hakimi, and Ms Laura Pinkerton for their assistance with this project.

\section{References}

Allen, M. (2010). The experience of connectivity. Information, Communication and Society, Vol. 13, 3, 350-374.

Bayne, S. and Ross, J., 2011. 'Digital Native'and 'Digital Immigrant'Discourses. In Digital difference (pp. 159-169). SensePublishers.

Biagi, F., and M. Loi. 2013. "Measuring ICT use and Learning Outcomes: evidence from recent econometric studies." European Journal of Education 48 (1): 28-42.

Biesta, G. (2013). Responsive or Responsible? Democratic Education for the Global Networked Society. Policy Futures in Education, Vol. 11, 6, 733-744.

Boonaert, T and Vettenburg, N (2011) Young people's Internet use: Divided or diversified? Childhood, Vol. 18,1, 54-66.

Boyd, D. (2014). It's Complicated: the social lives of networked teens. Yale: Yale University Press.

Buckingham, D. (1998). Children of the Electronic Age? Digital Media and the New Generational Rhetoric. European Journal of Communication, Vol. 13, 4, 557-65.

Buckingham, D. W., Banaji. S., Burn, A., Carr, D., Cranmer, S. \& Willett, R. (2006). The Media Literacy of Children and Young People: A Review of the Research Literature on Behalf of Ofcom. Retrieved from: http://stakeholders.ofcom.org.uk/binaries/research/media-literacy/ml_children.pdf

Clark, L. (2003). Challenges of Social Good in the World of "Grand Theft Auto" and "Barbie": A Case Study of a Community Computer Center for Youth. New Media \& Society. Vol 5, 1, 95-116.

Clark, L. S. 2012. Reflexivity in Data Analysis. The International Encyclopedia of Media Studies. 4:2:7.

Davies, C. \& Eynon, R. (2013). Teenagers and technology. Hove: Routledge.

Department of Education. (2013). Computing programmes of study: key stages 3 and 4 . National Curriculum of England. Retrieved from:

https://www.gov.uk/government/uploads/system/uploads/attachment_data/file/239067/SECONDA RY_national_curriculum_-_Computing.pdf

DiMaggio, P. \& Hargittai, E. (2001). From the 'Digital Divide' to 'Digital Inequality': Studying Internet Use as Penetration Increases. Retrieved from:

http://www.webuse.umd.edu/webshop/resources/Dimaggio_Digital_Divide.pdf

Eynon, R. \& Geniets, A. (2015). The digital skills paradox: how do digitally excluded youth develop skills to use the Internet? Learning, Media and Technology, Vol. 41, 3, 1-17

Eynon, R. \& Malmberg, L. (2012). A typology of young people's Internet use: Implications for education. Computers \& Education. Vol. 56, 3, 585-595. 
Facer, K., \& Furlong, R. (2001). Beyond the Myth of the 'Cyberkid': Young People at the Margins of the Information Revolution. Journal of Youth Studies, Vol. 4, 4, 451-469.

Friesen, N. (2008). Critical Theory: Ideological critique and the myths of e-learning. Ubiquity, Vol. 22, 9, 1-15.

Goode, J. (2010). The digital identity divide: how technology knowledge impacts college students. New Media \& Society, Vol. 12, 3, 497-513.

Gunkel, D. J. (2003). Second thoughts: Towards a critique of the digital divide. New Media and Society Vol. 5, 4, 499-522.

Greenhow, C \& Robelia, B. (2009). Informal learning and identity formation in online social networks, Learning, Media and Technology, Vol. 34, 2, 119-140.

Hargittai, E. (2002). Second-level digital divide: Differences in people's online skills. First Monday, Vol. 7, 4. Retrieved from:

http://firstmonday.org/htbin/cgiwrap/bin/ojs/index.php/fm/article/view/942/864

Hargittai, E. \& Hinnant, A. (2008). Digital Inequality Differences in Young Adults Use of the Internet. Communication Research, Vol. 35, 5, 602-621.

Holloway, S. L \& Valentine, G. (2003). Cyberkids: Children in the Information Age. London: Routledge.

Holmes, J. (2011). Cyberkids or divided generations? Characterising young people's Internet use in the UK with generic, continuum or typological models. New Media \& Society, Vol. 13, 7, 1104-1122.

Jenkins, H., Clinton, K., Purushotma, R., Robinson, A. J., \& Weigel, M. (2006). Confronting the Challenges of Participatory Culture: Media Education for the 21st Century. The John D. and Catherine T. MacArthur Foundation Reports on Digital Media and Learning. Cambridge, MA: MIT Press.

Jewitt, C. and Parashar, U. (2011). Technology and learning at home: findings from the evaluation of the Home Access Programme pilot. Journal of Computer Assisted Learning, Vol, 27,4, 303-313.

Livingstone, S., (2012). Critical reflections on the benefits of ICT in education. Oxford review of education, Vol. 38,1, 9-24.

Livingstone, S. \& Helsper, E. (2007). Gradations in digital inclusion: children, young people and the digital divide. New Media Society, Vol. 9, 4, 671-696.

Livingstone, S. \& Helsper, E. (2010). Balancing opportunities and risks in teenagers' use of the Internet: the role of online skills and Internet self-efficacy. New media \& society, Vol. 12, 2, 309-329.

Oblinger, D. \& Oblinger, J. (2005). Educating the Net Generation. Retrieved from: http://www.educause.edu/educatingthenetgen/.

Pagani, L., Argentin, G., Gui, M. \& Stanca L. (2016) The impact of digital skills on educational outcomes: evidence from performance tests, Educational Studies, 42:2, 137-162, DOI: 10.1080/03055698.2016.1148588

Peter, J. \& Valkenburg, P. (2006). Adolescents' Internet use: Testing the "disappearing digital divide" versus the "emerging digital differentiation" approach. Poetics, Vol. 34, 293-305.

Prensky, M. (2001). Digital Natives, Digital Immigrants Part 1. On the Horizon. Vol. 9, 5, 1-6. 
Richardson, L. \& Adams St. Pierre, E. (2005). Writing: A Method of Inquiry. In Denzin, N. K. \& Lincoln, Y. S. (2007). (Eds.) The SAGE Handbook of Qualitative Research. (3rd Ed.). London: Sage Publications, 959-978.

Robinson, L. (2009). A Taste for the Necessary. Information, Communication and Society. Vol. 12, 4, 488- 507.

Sachs, J. (2001) Teacher professional identity: competing discourses, competing outcomes, Journal of Education Policy, Vol. 16,2, 149-161.

Schofield-Clark, L., Demont-Heinrich, C. \& Webber, S. (2005). Parents, ICTs, and children's prospects for success: inter-views along the digital 'access rainbow'. Critical Studies in Media Communication Vol. 22, 409-426.

Selwyn, N. (2003). 'Doing IT for the kids': Re-examining children, computers and the 'Information Society'. Media, Culture and Society, Vol. 25, 3, 351-378.

Selwyn, N. (2004). Reconsidering Political and Popular Understandings of the Digital Divide. New Media \& Society. Vol. 6, 341-362.

Sims, C. (2014) From differentiated use to differentiating practices: negotiating legitimate participation and the production of privileged identities, Information, Communication \& Society, Vol. $17,6,670-682$.

Stake, R. E. (1995). The Art of Case Study Research. London: SAGE Publications.

Swanborn, P. (2010). Case Study Research: What, why and how? London: SAGE Publications.

Tripp, LM (2011). 'The computer is not for you to be looking around, it is for schoolwork': Challenges for digital inclusion as Latino immigrant families negotiate children's access to the Internet. New media \& society, Vol, 13, 4, 552-567.

Van Dijk. J. A. (1999). The Network Society: Social Aspects of New Media. London: Sage Publications.

Van Deursen, A \& Van Dijk, J.A. (2014). The digital divide shifts to differences in usage. New Media \& Society, Vol. 16, 3, 507-526.

Warschauer, M., Cotton, S, Ames, M. (2011) One Laptop per Child Birmingham: Case Study of a Radical Experiment International Journal of Learning and Media Spring 2011, Vol. 3, No. 2, Pages: 6176.

Warschauer, M and Matuchniak, T (2010). New technology and digital worlds: Analyzing evidence of equity in access, use, and outcomes Review of Research in Education, 